\title{
Potencialidade da cultura do quiabeiro (Mbelmoschus esculentus L. Moench) em Manaus - AM (*)
}

\author{
Carlos Roberto Bueno (**)
}

\begin{abstract}
Resumo
Tentando-se detectar material promissor para o Programa de Melhoramento da Produção de Hortaliças da Amazônia, desenvolvido pelo INPA, foi realizado o presente estudo, incluindo-se onze diferentes variedades e populações de quiabeiro. Pelos resultados obtidos, pode concluir-se que mesmo na época de menores precipitações pluviométricas é possível cultivar essa planta em terra firme com resultados satisfatórios, alcançando-se produtividades (média e estimada) de 8,51. 7,78, $7,09,5,74$ e 5,35 toneladas de frutos frescos por hectare, respectivamente para Jari, Aripuanã I, Campines n.o 1, Várzea e Aripuanã II (sem diferenças estatistica entre elas) que se apresentaram mais promissoras para a região de Manaus.
\end{abstract}

\section{INTRODUÇÃO}

O quiabeiro (Abelmoschus esculentus L. Moench) é uma planta tropical, anual, da família dás Malváceas, possuindo flores hermafroditas, reproduzindo-se normalmente por autopolinização, podendo, entretanto, ocorrer a polinização cruzada em taxas de $4 \%$ a $32 \%$ ou mesmo até $42,2 \%$ (Mitidieri \& Vencovsky, 1974). Segundo Crawford (1966) e Franco (1960 e 1968) a composição por 100 gramas de fruto fresco é a seguinte :

$\begin{array}{ll}\text { Água } & 90 \% \\ \text { Calorias } & 38,6 \\ \text { Proteínas } & 1,80 \mathrm{~g} \\ \text { Lipídeos } & 0,20 \mathrm{~g} \\ \text { Hidratos de Carbono } & 7,40 \mathrm{~g} \\ \text { Calcio } & 62 \mathrm{mg} \\ \text { Ferro } & 0,50 \mathrm{mg} \\ \text { Fósforo } & 19 \mathrm{mg} \\ \text { Vitamina A } & 741 \mathrm{UI} \\ \text { Tiamina } & 0,06 \mathrm{mg} \\ \text { Riboflavina } & 0,06 \mathrm{mg} \\ \text { Niacina } & 0,8 \mathrm{mg} \\ \text { Ácido Ascórbico } & 20 \mathrm{mg}\end{array}$

Alguns centros de pesquisa têm obtido boas variedades, através de cruzamentos controlados, porém os próprios agricultores locais vêm produzindo suas sementes, em um processo lento de seleção e portanto o material atualmente cultivado na região tem sua origem desconhecida; daí denominarmos de "população local".

O problema limitante para o cultivo do quiabeiro todo $\mathrm{c}$ ano parece ser a falta de água em determinadas épocas (Filgueira, 1972), principalmente em regiões com período chuvoso e seco definido, como ocorre no Estado do Amazonas, sendo considerado de maio a outubro como o período de "verão", ou seja com menores precipitações pluviométricas. O cultivo do quiabeiro restringe-se às várzeas dos rios Solimões e Amazonas, porém a disponibilidade de área é somente durante poucos meses do ano, suficientes para apenas um plantio; daí a instabilidade dos preços do produto no mercado. Noda (1978) demonstrou ser possível produzir-se quiabo em terra firme na época seca, com a utilização de irrigação artificial.

C objetivo do presente estudo foi detectar aquelas variedades ou populações de quiabeiro mais promissoras para a região, para então, através de métodos com base genética de cruzamentos e seleção, tentar reunir características agronomicamente desejáveis, obtendo-se, assim, novas variedades, mais adaptadas às nossas condições de terra firme e com maior resistência à seca resultando em uma maior produtividade.

\section{MATERIAIS E MÉTODOS}

Foram testadas onze variedades e populações, cujas sementes foram fornecidas por firmas produtoras ou coletadas na região e encontram-se relacionadas na tabela abaixo.

(*) - Com o apoio do POLAMAZÔNIA - Programa de Polos Agropecuários e Agrominerais da Amazônia. Projeto 2048. (*) - Instituto Nacional de Pesquisas da Amazônıa, Manaus. 
TABELA 1 - Caracterização das variedades e populaçōes de quiabeiro utilizadas no ensaio de campo.

\begin{tabular}{|c|c|c|}
\hline $\begin{array}{l}\text { Identifica- } \\
\text { ção (IH) * }\end{array}$ & $\begin{array}{l}\text { Variedade ou } \\
\text { população }\end{array}$ & Origem \\
\hline 178 & Campinas $n \cdot \circ 2$ & Piracicaba-SP \\
\hline 273 & Várzea & Careiro-AM \\
\hline 446 & Aripuanã 1 & Aripuanã-MT \\
\hline 495 & Santa Cruz 47 & Bragança Paulista-SP \\
\hline 544 & Jari & Jari-PA \\
\hline 719 & Green Velvet & Brasilia-DF \\
\hline 720 & UFV 1144 & Viçosa-MG \\
\hline 722 & Campinas n.० 1 & Piracicaba-SP \\
\hline 723 & Seleção Primavera & Brasília-DF \\
\hline 860 & Aripuanã II & Aripuanā-MT \\
\hline 1033 & Chinês & Aripuanä-MT \\
\hline
\end{tabular}

(*) - Referência de "Introduçẫo de Hortaliças".

O delineamento experimental foi de blocos ao acaso com 4 repetições, cada parcela contando com 10 plantas úteis. O plantio foi realizado no dia 13 de abril de 1978, utilizando-se espaçamento de $1,00 \times 0,50 \mathrm{~m}$ e a adubação constou apenas $40 \mathrm{~g}$ de Superfosfato Triplo por metro linear de sulco, em uma área onde havia sido aplicado calcáreo na base de 2 ton/ha, em solo de textura pesada, localizado no Colégio Agrícola de Manaus, $\mathrm{Km} 8$ da Estrada do Aleixo.

Quinzenalmente, até o início da fase de coIheita foram adicionados $5 \mathrm{~g} /$ planta de uréia. A Tabela 2 revela os dados de fertilidade do solo na área em que foi desenvolvido o presente estudo. Os problemas fitossanitários verificados no ensaio foram considerados desprezíveis, não sendo necessário nenhum tratamento, revelando que a cultura já apresenta resistência quanto ao ataque de pragas e dcenças.

A fase de colheita iniciou-se em 28 de junho, prolongando-se até 6 de setembro de 1978 .

Os dados climáticos considerados foram obtidos no Posto Metereológico do INPA, situado na Reserva Ducke, Rodovia Manaus-Itacoa- tiara. A estimativa de evapotranspiração potencial foi calculadia pelo método de Thornthwaite (1948) e ajustada à duração real do dia para a nossa região, através de tabelas propostas por Camargo (1960).

$E=1,6(10 \cdot T / I)^{a}$

$$
\begin{aligned}
& I=\sum i \\
& i=(T / 5)^{1.514}
\end{aligned}
$$

onde: $a=0,000000675 \mathrm{l}^{3}-0,0000771 \mathrm{l}^{2}+$ 0,01792 I $+0,49239$

e significam que :

$E$ = evapotranspiração potencial não ajustada.

$\mathrm{T}=$ temperatura média mensal $\left({ }^{\circ} \mathrm{C}\right)$.

$\mathrm{a}=$ constante que varia com a localidade.

$\mathrm{I}=$ indice térmico anual.

$\mathrm{i}=$ índice térmico mensal.

Os dados finais obtidos foram analisados estatisticamente por computador, através do Centro de Processamento de Dados do INPA.

\section{REsultados E Discussão}

Os resultados obtidos são mostrados na Tabela 3.

A figura 1 e Tabela 4 mostram a distribuição da temperatura média $\left({ }^{\circ} \mathrm{C}\right)$, precipitação pluviométrice $(\mathrm{mm})$, evapotranspiraçã̃o potencial ajustada $(\mathrm{mm})$ e balanço hídrico $(\mathrm{mm}) \mathrm{du}$ rante o período do ensaio no campo. Sempre que o total pluviométrico no período for maior que a evapotranspiração potencial, o balanço hídrico será positivo e haverá acúmulo de água no solo até os limites considerados, quando passam a ocorrer os excedentes, não aproveitados pela planta. Quando o balanço apresentar-se negativo, isso implica que toda a água foi consumida e ocorreu deficiência hídrica no período. A temperatura média apresentou pouca variação no período do estudo. Através da

TABELA 2 - Dados sobre análise do Solo na área do ensaio. (EMBRAPA - UEPAE/MANAUS)

\begin{tabular}{ccccccc}
$\% \quad \mathrm{C}$ & $\frac{\mathrm{pH}}{\mathrm{H}_{2} \mathrm{O}}$ & $\frac{\mathrm{PO}_{4}}{\mathrm{ppm}}$ & $\frac{\mathrm{Al}+++}{\mathrm{e} \mathrm{mg} / 100} \frac{\mathrm{Mg}++}{\mathrm{ml}}$ & $\frac{\mathrm{TFSA}}{\mathrm{Ca}++}+\mathrm{Mg}++$ \\
\hline 1,0 & 4,6 & 1,9 & 1,1 & 0,6 & 2,5 \\
\hline
\end{tabular}




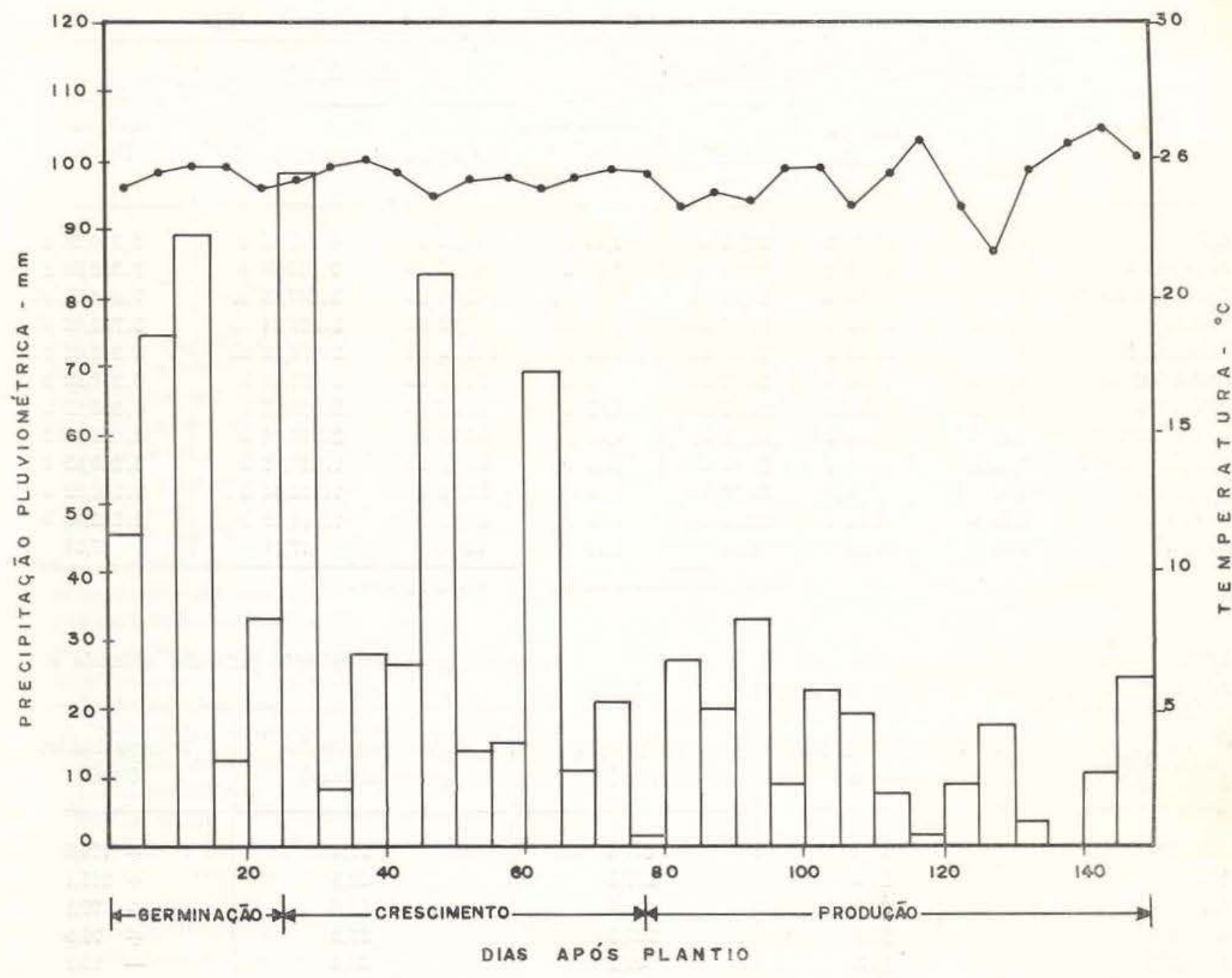

Fig. 1 - Distribuição da temperatura média e precipitação pluviométrica acumulada por pêntadas, verificadas em Ma. naus (13/04 a 06/09/78), sendo indicados os períodos de germinação, crescimento vegetativo e produção na cultura do quiabeiro.

análise conjunta da Figura 1 e Tabela 4, verificamos que, durante o ciclo da cultura, houve apenas um período de deficiência hídrica, na fase de produção, porém é provável que isso ocorreu também em períodos menores, não revelados pela estimativa da evapotranspiração potencial dada a metodologia utilizada.

Analisando a Tabela 3, verificamos que com relação às características do fruto e principalmente altura das plantas a variedade "Chinês" diferiu significativamente das demais, porém teve baixa produção, o que nos levará à redução do espaçamento, aumentando a população de plantas por área. As populações Jari e Aripuanã I produziram respectivamente 8,51 e 7,78 ton/ha de frutos frescos, porém não diferiram significativamente das variedades Campinas $n^{0}$ 1. Várzea e Aripuanã II que produziram 7,09, 5,74 e 5,35 toneladas/ha de frutos frescos, respectivamente, mas a produção foi maior que as demais variedades e populações do ensaio.

\section{SUMMARY}

The present study was carried out as part of INPA's program to improve vegetable production in Amazonia. Eleven different varieties and populatiens of Okra were tested. From the results obtained it can be concluded that even in the dry season it is possible to cultivate this plant satisfactorily on high land (terra fir- 
TABELA 3 - Resultados obtidos som a cultura do quiabeiro em Manaus - AM.

\begin{tabular}{|c|c|c|c|c|c|c|c|}
\hline \multirow{2}{*}{$\begin{array}{l}\text { Variedade } \\
\text { ou } \\
\text { populaçăo }\end{array}$} & \multicolumn{3}{|c|}{ Características do fruto (média) } & \multirow{2}{*}{$\begin{array}{c}\text { Altura } \\
\text { média da } \\
\text { planta (m) }\end{array}$} & \multicolumn{2}{|c|}{ Parcela } & \multirow{2}{*}{$\begin{array}{c}\text { Produtividade } \\
\text { estimada } \\
\text { (kg/ha) }\end{array}$} \\
\hline & $\begin{array}{l}\text { Diâmetro } \\
(\mathrm{cm})\end{array}$ & $\begin{array}{l}\text { mento } \\
\text { (cm) }\end{array}$ & $\begin{array}{l}\text { Peso } \\
\text { (g) }\end{array}$ & & N. 0 frutos & Produção (g) & \\
\hline Jari & $1,57 \mathrm{~b}$ & 14,61 a & 25,86 a & $1,48 a b$ & 161,25 a & $4.255,27$ a & $8.510 .54 \mathrm{a}$ \\
\hline Aripuanã I & $1,64 \mathrm{~b}$ & $14,43 \mathrm{a}$ & 26,97 a & 1,61 a & $143,25 a b$ & $3.890,30 \mathrm{a}$ & $7.780,59 \mathrm{a}$ \\
\hline Campinas $n \cdot 01$ & $1,56 \mathrm{~b}$ & 14,15 a & $23,71 \mathrm{ab}$ & $1,35 \mathrm{ab}$ & $149,50 \mathrm{ab}$ & $3.547,28 \mathrm{ab}$ & 7. $094,55 \mathrm{ab}$ \\
\hline Várzea & $1,52 \mathrm{~b}$ & 14,25 a & $22,86 \mathrm{ab}$ & $1,39 a b$ & $137,75 a b$ & $2.870,24 a b$ & $5.740,48 \mathrm{ab}$ \\
\hline Aripuanā II & $1,54 \mathrm{~b}$ & $13,37 \mathrm{a}$ & $22,67 \mathrm{ab}$ & $1,32 \mathrm{ab}$ & $119,75 \mathrm{ab}$ & $2.674,22 \mathrm{ab}$ & $5.348 .45 \mathrm{ab}$ \\
\hline Green Velvet & $1,64 \mathrm{~b}$ & 13,87 a & $22,42 a b$ & $1,28 \mathrm{ab}$ & $98,00 \mathrm{ab}$ & $2.031,00 \mathrm{~b}$ & $0.061,99 \mathrm{~b}$ \\
\hline UFV 1144 & $1,87 \mathrm{a}$ & 14,22 a & $23,18 \mathrm{ab}$ & $1,13 \mathrm{~b}$ & $97,25 \mathrm{ab}$ & $2.030,06 \mathrm{~b}$ & $4.060,12 \mathrm{~b}$ \\
\hline Santa Cruz 47 & $1,67 \mathrm{~b}$ & 14,12 a & $24,92 a b$ & $1,15 \mathrm{~b}$ & 86,25 b & $2.010,04 \mathrm{~b}$ & $4.020,07 \mathrm{~b}$ \\
\hline Campinas $n \cdot 2$ & $1,56 \mathrm{~b}$ & 14,61 a & $20,13 \mathrm{~b}$ & $1,32 a b$ & $95,00 \mathrm{ab}$ & $1.824,76$ b & $3.649,53 \mathrm{~b}$ \\
\hline Primavera & $1,65 \mathrm{~b}$ & $14,30 \mathrm{a}$ & $22,56 \mathrm{ab}$ & $1,33 \mathrm{ab}$ & 83,75 b & $1.773,44 \mathrm{~b}$ & $3.546,89 \mathrm{~b}$ \\
\hline Chinês & $2,33 \mathrm{a}$ & $9,75 \mathrm{~b}$ & $22,02 a b$ & $0,56 \mathrm{c}$ & 84,25 b & $1.530,23 \mathrm{~b}$ & $3.060,45 \mathrm{~b}$ \\
\hline CV $(\%)$ & 3,86 & 5,30 & 5,04 & 6,17 & 12,94 & 17,01 & 17,01 \\
\hline
\end{tabular}

Teste de Tukey - As médias separados por uma letro diferem significativamente $(P \geq 0,05)$.

TABELA 4 - Valores de temperatura média do ar, precipitação acumulada, evapotranspiração potencial ajustada e balanço hídrico no período do ensaio de campo.

\begin{tabular}{|c|c|c|c|c|}
\hline Meses & $\begin{array}{c}\text { Temperatura }\left({ }^{\circ} \mathrm{C}\right) \\
\text { média }\end{array}$ & $\begin{array}{l}\text { Precipitaçăo } \\
\text { (mm) }\end{array}$ & $\begin{array}{c}\text { Evapotranspiração } \\
\text { potencial }(\mathrm{mm})\end{array}$ & $\begin{array}{c}\text { Balanço hídrico } \\
\text { (mm) }\end{array}$ \\
\hline ABRIL • & 24,4 & 217,0 & 37,4 & $+179,6$ \\
\hline MAIO & 24,4 & 277,9 & 62,8 & $+215,1$ \\
\hline JUNHO & 24,2 & 138,6 & 61,5 & +77.1 \\
\hline JULHO & 23,9 & 133,8 & 57.2 & $+76,6$ \\
\hline AGOSTO & 24,3 & 41,8 & 61,4 & - 19,6 \\
\hline SETEMBRO * & 25,9 & 45.8 & 13,7 & $+32,1$ \\
\hline
\end{tabular}

(*) - Considerando openas o período do ensaio.

me). Average productivities of $8.51,7.78,7.09,5.74$ and 5.35 tonnes of fresh fruit per hectare were calculated for Jari, Aripuană I, Campinas n.o 1, Várzez and Aripuanã II respectively (without a statistically significant difference between them). These populations seem to be the most promising for the Manaus region.

\section{BIBLIOGRAFIA}

\section{Camargo, A.P. DE}

1966 - Contribuição para a determinação da Evapotranspiraçăo potencial no Estadio de São Paulo. Boletim do Instituto Agronômico de Campinas, (161) : 1-60.

CRAWFORD, A.M.D.

1966 - Alimentos, Seleção e Preparo. Rio de Janeiro. Distribuidora Record de Serviços de Imprensa, $387 \mathrm{p}$.
Filguetra, F.A.R.

1972 - Manual de Olericultura. São Paulo. Editora Agronômica Ceres, 451 p.

Franco, G.

1960 - Tabela de Composição Química de Allmentos. Rio de Janeiro. (SASP), 194 p.

1968 - Teor Vitaminico de Alimentos. Rio de Janeiro. Livraria José Olympio Editora, i41 p.

Mitmieri, J. \& VencovsKY, R.

1974 - Polinização cruzado do quiabeiro em condiçōes de campo. Rev. Agric., 49(1) : 3-6.

NODA, $\mathrm{H}$.

1978 - A cultura do quiabeiro em Manaus. Em "Cultivo de soja e espécies olerícolas no Amazonas". INPA. Manaus, $155 \mathrm{p}$.

Thorntwaite, C.W.

1948 - An approach toward a rational classification of climate. Geogr. Rev., 38 : 55-94.

(Aceito para publicação em $3 / 4 / 80$ ) 